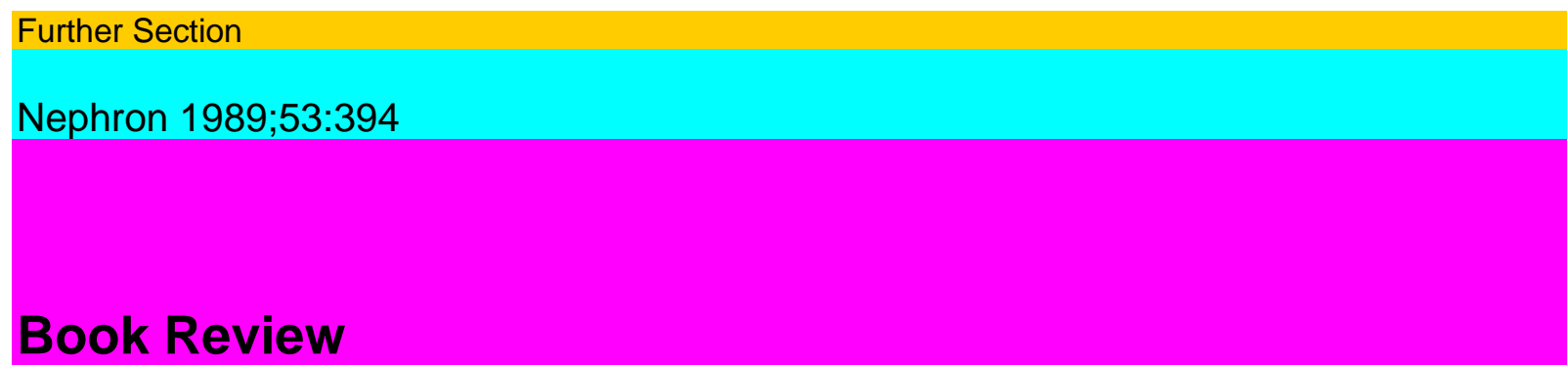

\title{
T. Halper
}

The Misfortunes of Others

Cambridge University Press, New York 1989 Approx. E25.00 ISBN 0-521-35047-6

This book is a scientific investigation into End Stage Renal Disease Services in the United

Kingdom. From its title, a quotation from the famous maxims of the Marquise de la

Rochefoucauld, 'we all have the strength to bear the misfortunes of others', it would appear that perhaps the author would abandon the purely political scientific analysis of his subject, and indeed in the last paragraph on the last page of text he comes down clearly on the side of humanity. Generally however, the book carefully examines, in a detached scientific manner in four chapters, the situation of end-stage renal disease in the United Kingdom, the macroallocation of funds to the ESRD service and the microallocation of funds in the way patients are selected for treatment, and finally a chapter on 'premature conclusions'.

The author is remarkably well informed as to how the DHSS is structured, how British government decisions are made, and the changing attitude of the nephrologists in the UK. He does not mention the merit award system and the honors system, both of which tend to keep the nephrologist in line and not rocking the boat - in addition to peer pressure and norms of British behavior.

The book is beautifully written, and is scientifically laden with illuminating footnotes and references. It is also a very disturbing book. Which nephrologist is capable of treating his individual patients as one of a herd? One's Hippocratic oath obliges one to

prolong the life of the individual patient, as Dr. Halper points out. The major problem is in the allocation of inadequate funds to the NHS despite an increase in the strength of the British economy. Dr. Halper alludes to the occasional moves made by the Thatcher government to increase ESRD funding but one is mystified by how the current white paper's proposing transforming the NHS will affect the ESRD program, and the consequences may be disastrous. The USA attitude for the past fifteen years, is that health care in ESRD has to be provided for all who can benefit from it. This is commendable, but even in the USA the cost saving of the NHS is help up as admirable by the essentially amoral administrators, and clearly adoption of Mrs. Thatcher's economics will erode the USA ESRD program sooner or later. The writing is on the wall. The UK government on the other hand needs to allocate a greater part of its GNP to health care, and to cease being the dialysis Cinderella of Europe. Mrs. Thatcher can initially reduce massive defense spending. She should concentrate her efforts on finding political solutions to the grave problems of Nothern Ireland and the Falklands. Some of the money thus saved could be applied to larger allocations to the NHS and to improving the lot of the population in general and to provide adequate ESRD funding in particular.

In summary, a scholarly dispassionate disturbing book dealing thorougly with a difficult subject. It should be compulsory reading for all nephrologists and physicians in the UK, and all health administrators throughout the world, and particularly in the USA. One final note - for this 
reviewer at least, this statement of the Marquise de la Rochefoucauld is incorrect. The misfortunes of others are deeply disturbing and troublesome. No man is an island.

G.M. Berlyne

Announcement

27th Congress of the European Dialysis and Transplant Association (EDTA)European Renal Association (ERA)

Vienna, September 5-8,1990

For further information, please contact:

EDTA/ERA Congress

c/o Medizinische Akademie

Alserstrasse 4

A-1090 Vienna (Austria)

Telephone: (Austria) 222-4313-0

Telex: (Austria) -134743 Medaka 